\title{
Workflow Embedded Training in the IT Sector ${ }^{1}$
}

\author{
Matthias Rohs \\ Fraunhofer Insitute for Software and Systems Engineering (ISST), Mollstrasse 1, D-10178 \\ Berlin, Germiny \\ matthias.rohs@isst.fhg.de
}

Keywords: government, didactics, further education, catalyst for changes, in-service training

\begin{abstract}
On the one hand, the rapid innovation cycles lead to a considerable lack of ITspecialists. On the other hand, there are more than 32,000 unemployed ITspecialists and 60,000 unemployed engineers in Germany. These trends can also be ascribed to a quasi non-existent concept of IT-Training. To solve these problems and close the gap caused by the lack of IT-specialist an association of representatives of employers and unions ('Bündnis für Arbeit') have initiated a re-structuring of advenced vocational training for the IT-sector. The Fraunhofer ISST has been commissioned to develop a concept for putting this system into practice. Under the title 'Further Professional Education based on Working Processes' (APO 2001), a concept which is work-integrated and based on business processes is to be developed in collaboration with industrial partners and educational institutes.
\end{abstract}

\section{INTRODUCTION}

Rapid technological development in the IT-sector leads to a considerable shortage of qualified IT-specialists. Currently, there is a lack of 70,000 ITexperts in Germany. According to experts, there will be a demand of 1.1 million experts in the field of IT-related technology till the year 2010. With

${ }^{1}$ This research was supported by the German ministry of research and technology $(b m b+f)$ as part of the research project 'APO' (2001). 
existing 800,000 specialists in mind, 50,000 qualified IT-experts $p$. a. will be needed (Petersen and Wehmeyer 2000).

But there are only 5,000 to 8,000 graduates from universities and technical colleges p. a. and there will be 60,000 graduates from IT-related vocational training courses by the year 2003. So Germany has - according to a survey (Bitkom 2001) - the largest need of IT experts as compared to all other Western European countries.

This lack cannot be solved in the long run, even with the 20,000 'Green Card specialists' from abroad (currently 5,000).

One reason for that dilemma is that there is no real system for ITqualification apart from university (Figure 1). Universities are not able to cope with the need for IT-specialists and there are no other high-quality courses in addition to IT-vocational training.

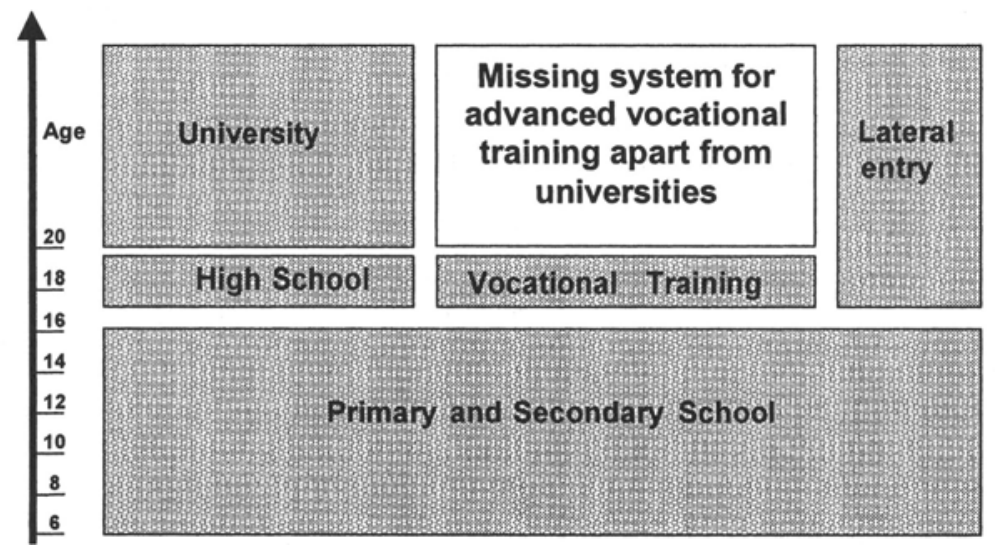

Figure 1. German system of vocational and further vocational education in the sector of IT

In order to solve this problem in the medium-term, the German Federal Ministry for Education and Research (BMB+F) has initiated the set-up of a Regulation Procedure for structuring the further education system. This procedure is carried out by the German Federal Institute for Vocational Training (BiBB). In collaboration with IT-experts, quality standards will be conceived which are aligned to the requirements of the industry. Graduates from IT-related training courses, university dropouts and unemployed ITspecialist are the target groups. They will be offered new carrier prospects by means of further education. (Grunwald and Rohs 2000). 


\section{THE NEW GERMAN STRUCTURE OF FURTHER VOCATIONAL TRAINING IN THE IT SECTOR}

As a first result of the Regulation a structure was developed. In this structure about 30 profiles on three levels are defined: specialists, e.g. network administrators, operative professionals and strategic professional profiles (Figure 2). While doing so, several qualification profiles are each summed up and merged with the respective higher level. Degrees on the level of the operative professionals are thought to be comparable with a Bachelor degree, strategic professionals have a qualification similar to a Master degree.

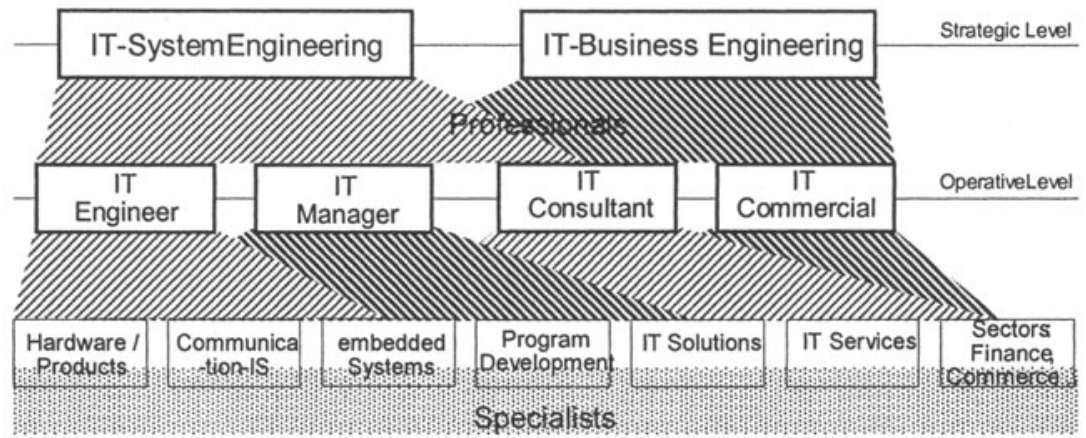

Figure 2. New Structure frr Advanced Vocational Training in the Sector of IT in Germany

The Fraunhofer Institute for Software and System Engineering (ISST) has been commissioned by the German Federal Ministry for Education and Research $(\mathrm{BMB}+\mathrm{F})$ to develop a concept for the realisation of this structure. This project is called APO (2001): Arbeitsprozessorientierte Weiterbildung (Workflow Embedded Training); it should develop a didactic base as a guideline for workflow embedded training courses in the IT sector. 


\section{DIDACTIC CONCEPT}

The basis of the didactic concept are the requirements of the IT-branch and the recommendations of the association of representatives of employer and unions. The goal is to develop a workplace-oriented concept for ITtraining.

\subsection{Requirements}

The basic requirements of a didactic model for further education also result from the requirements of the IT-sector. So the IT-specialists must cope with changed objectives and different working environments. They work in interdisciplinary teams and increasingly customer-oriented. Therefore it is necessary for them to:

- Improve their professional skills

- Strengthen their social capabilities

- Develop auto-didactic capabilities.

Moreover, IT-specialists are urgently needed experts who can only rarely be taken out of the production process. However, the need for advanced vocational training is very high to special skills for information technology. Therefore advanced vocational training must take place in the working process through learning-by-doing. Thus acquired knowledge is mostly product- and project-oriented. These learning strategies are common because they comply with the demands of the IT branch. We intend to integrate them in a didactic concept. Furthermore, the basic concept has to pay attention to developing self-learning strategies and to impart the fundamentals of information technology. With these capabilities an IT specialist will be able to keep up with the technical progress. As a result the educational concept has to be

- Embedded in the companies' workflow

- Oriented on the practice

- Adapted to the individual skills

- Oriented on competencies. 


\subsection{Workflow orientation}

The goal of the APO (2001) Project is to embed vocational training within the workflow and to consider individual learning efforts as a part of learning organisation (Dehnbostel 2000, Albrecht 1999). IT-technicians will be trained on-the-job and on-demand in a project-like manner.

Within the working process learning is always stimulated when employees are confronted with new or difficult tasks. But those informal learning processes occur unsystematically and without any outward signs (Livingstone 1999, Kirchhöfer 2000). In contrary to this, curricular vocational training-measures are more structured and transparent but they do not correspond with the tasks and demands of the processes.

\subsection{Reference projects}

A workflow-embedded approach relies on objectives that are based on practical experience. Therefore fundamentals of our concept are real-work assignments. But these practice projects are very different so that there is no quality standard for the qualification as a whole.

That's why the key element of our concept is so-called reference projects. They represent typical and ideal work processes of a professional profile. In cooperation with well-known IT-enterprises we identify and analyse suitable projects. For example: the basis of the reference project for a software developer was the development of an e-commerce system carried out by Software $A G$ (Tübingen).

Projects are suitable when they are up-to-date, documented, complete, typical and instructive. It is also possible to combine parts of different projects, e.g. the processes 'change management' and 'performance management' for a network administrator. The reference project is not a case study but a generic scheme of a professional and thus a profound basis for workflow embedded training.

The reference project has at least three functions:

- It enables the assignment of knowledge to a certain professional field

- It serves as a model to apply tools and methods and carries out own projects and

- It serves as a quality standard for vocational training by means of a certain profile.

The reference project has the task to close the gap in the workflow between the work assignment and the requirements of advanced vocational training. This allows the adaptation of the individual learning assignments but will also lead all participants to a homogeneous competence level (Figure 3). 


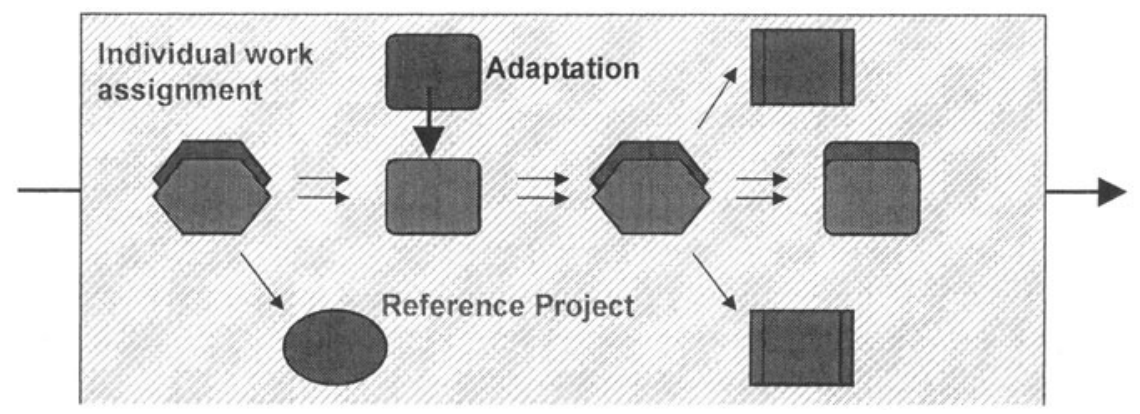

Figure 3. Adaptation of individual work assignments

\section{IMPLEMENTATION}

The strong focus on the practice-oriented tasks requires a basic concept of instruction and assistance. Major problems are the different general conditions for its realisation between companies, e.g. the learning culture and the size of an enterprise, the number of participants, the possibilities to support the learner, suitable work assignments and many more. Thus an important attribute of the concept is flexibility to suit for different general conditions.

\subsection{Learning arrangement}

The arrangement of the implementation is oriented on the decentralised human resources development approach (Staudt and Kriegesmann 1999). Superiors are the key figures. They are interested in well-qualified staff, know individual abilities and are able to provide the conditions for learning on the workplace. But in most cases the superiors aren't able to manage further education by themselves. Participants need help for special questions and support for the organisation of the learning process. That's why specialists, mentors and trainers support the learner together.

In this way the resources of an enterprise can better be used for its own human resource development. Therefore the APO-concept is not only a contribution to a learning organisation but also support and an incentive.

But these model can not be achieved in all cases because there is either no qualified staff to give the learner sufficient feedback or the organisation of the learning process is inappropriate. If so, external specialists can attend to these part(s). For small enterprises it could be useful to build (specific) networks to support one another. In this way one trainer or one specialist can 
instruct participants of different enterprises. Special internet tools can support communication and collaboration.

\subsection{Informal and self-oriented learning}

The aim is to coach and accompany the participants in their learning processes rather than to teach them detailed information. Most of them are highly experienced. What they lack is a certification of their qualification. The practice and the reflection of this experience are the basis for the instruction of theoretical complexes. That's why a revision of experience and reflection is the basis for the learning process.

The teaching of fundamental knowledge for certain qualifications is conducted by short courses and specifically supported by teaching adequate knowledge.

The adaptation of these general qualifications to the specific requirements of the respective company are done by a mentor. This procedure supports both the participant's active competence and the transfer of the skills into the daily working routine.

\subsection{Media resources}

Even though instruction remains obligatory in APO-oriented vocational training, conventional instructional resources like books, manuals and static web sites become more and more obsolete.

- Content is getting more unique and very specific; instructional resources to guide and support the learning process should also be conceived that way.

- Learning environments are proprietary, much information needed to transform knowledge from theory into practice is company-specific and only destined for internal use. Instructional resources that may accelerate this knowledge transfer must include domain-specific and companyspecific knowledge.

- Real-world problems must be solved within reasonable time; e.g. a network administrator must be able to reconfigure a router in a short time. Instructional resources that enable an IT technician to learn about router configuration on-the-job must be made available within hours or even minutes.

These requirements cause a demand for instructional resources that are highly adaptive, highly integrative and can be produced on-demand. Recent approaches which support the on-demand selection and sequencing of modular learning resources (e.g. Caumanns 2000) seem to be suited well to provide the flexibility needed for this new kind of instructional material. 


\section{SUSTAINABILITY}

Because of the rapid development in the IT-sector, sustainability is a central issue for instructional quality. Therefore it is not only instruction but also the suggestion that self-learning competencies to update knowledge effectively on the job is the primary aim of the concept.

It is necessary to find a way to merge informal learning processes and instructive elements.

\section{1 $\quad$ Fading}

The ultimate goal is to support the participants in the process of developing auto-didactic skills and not to suppose that they are a given fact. To achieve this, media, methods and the organisational structure of the qualification process are increasingly adapted to authentic working conditions. That means that the trainer who teaches basic knowledge at the beginning gradually supervises and assists the learning process on demand. Participants should successively organise their own comprehension processes, practice their own skills and use tools, e.g. search engines instead of didactically prepared teaching material (Figure 4). This method is part of a basic approach thought to develop skills and is oriented to the basic approach of 'Cognitive Apprenticeship' (Brown, Collins and Duguid 1998).

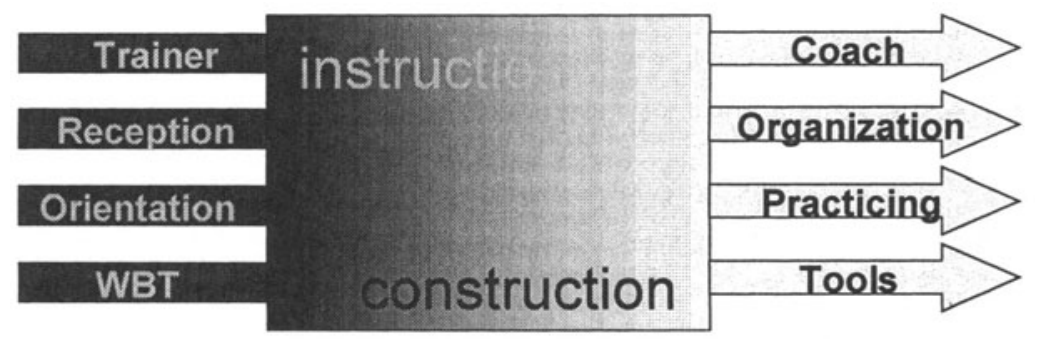

Figure 4. Fading

\section{PERSPECTIVE}

Our didactical concept is adapted to certain professional profiles within the IT-branch. Along with special recommendations for its realisation this draft is documented in a manual. This manual is thought to be the basis for the implementation of future training courses. The recommendations in the 
manuals allows companies to train IT-specialists independent from producers and saving quality standards.

A first course based on APO (2001) will be carried out by German Telekom AG in the Summer 2001. About 15 employees will qualify to network administrators by training them individually and on the job.

\section{REFERENCES}

APO (2001) [http://www.apo-it.de].

Albrecht, G. (1999) Personenqualifizierung im Kontext neuer Lernwelten. BertelsmannVerlag, Bielefeld.

Bitkom (2001) Kein Ende des Mangels an IT- und E-Business-Spezialisten absehbar. Press Release. [http://www.bitkom.net/presse/presseinformationen/060301.html] 3.05.2001.

Brown, J. S., Collins A. and Duguid P. (1998) Situated Cognition and the Culture of Learning. Educational Researcher, Issue 1, pp. 32-43.

Bundesanstalt für Arbeit und Sozialordnung - BAM (2001) Informationen zum Fachkräftebedarf in Deutschland. [http://www.bma.de/de/aktuel1/thema/it1.htm] 3.05.2001.

Caumanns, J. (2000) Bottom-Up Generation of Hypermedia Documents. Multimedia Tools and Applications. Vol. 12, November, Issue 2/3, pp. 109-128, Kluwer Academic Publishers.

Dehnbostel, P. (2000) Erfahrungslernen in der beruflichen Bildung: Ansatzpunkte für eine neue Lernkultur? In Arbeits- und erfahrungsorientierte Lernkonzepte, P. Dehnbostel and H. Novak (eds.), Bertelsmann, Bielefeld.

Garrik, J. (1998) Informal Learning in the Workplace: Unmasking Human Ressource Development.

Grunwald, S. and Rohs M. (2000) Arbeitsprozessorientierung in der IT-Weiterbildung. Berufsbildung in Wissenschaft und Praxis, Heft 6, pp. 22-24.

Kirchhöfer, D. (2000) Informelles Lernen in alläglichen Lebensführungen. QUEM-report, Issue 66.

Livingstone, D. W. (1999) Informelles Lernen in der Wissensgesellschaft: Erste kanadische Erhebung über informelles Lernverhalten. In Quem-report: Kompetenz für Europa: Wandel durch Lernen - Lernen durch Wandel, Heft 60, pp. 65-91.

Marsick, V. J. and Watkins, K. E. (1990) Informal and incidental learning in the workplace. Routledge, London.

Petersen, A. W. and Wehmeyer, C. (2000) Die neuen IT-Berufe auf dem Prüfstand: Erste Ergebnisse der bundesweiten IT-Studie. Berufsbildung in Wissenschaft und Praxis, 29 (6), pp. 7-12.

Staudt, E. and Kriegesmann, B. (1999) Weiterbildung: Ein Mythos zerbricht. In Arbeitsgemeinschaft Qualifikations-Entwicklungs-Management. Kompetenzentwicklung '99, QUEM (eds.), Waxmann Verlag, pp. 17-60. 


\section{BIOGRAPHY}

Matthias Rohs studied pedagogy, sociology and psychology with an emphasis on media psychology and media didactics at Freie Universität Berlin. Parallel to this he has worked as an assistant at the Department of Mathematics and Computer Science in the field of multimedia. His diploma thesis was in the field of learning software for vocational training. Since 2000 he has been a member of the scientific staff at the Fraunhofer Institute for Software and Systems Engineering and has been responsible for designing didactic concepts. 